\title{
The Northern Sea Route in the conditions of the global economic environment of the transport market
}

\author{
Dmitry Kuzmin ${ }^{1, *}$, Andrei Baginov ${ }^{1}$, and Sergey Levin ${ }^{1}$ \\ ${ }^{1}$ Russian University of Transport (Moscow Institute of Railway Engineering (MIIT), Obrazcova \\ str.,9, b.9,127994, Moscow, Russia
}

\begin{abstract}
The paper discusses the prospects for the use of the Northern Sea Route as an option of the transit cargo transportation in international traffic in the conditions of the development of alternative means of communication and the global economic environment of the transport market. The reasons for the low demand for the Northern Sea Route are analyzed. The demand for transportation is predicted.
\end{abstract}

\section{Introduction}

The modern transport market is a highly competitive environment. The processes of globalization, development of transport technologies and unification of transport processes have created a competition of a completely different level. Around 15-20 years ago, competition in the transport market was mostly microeconomic, local in nature and was characterized by the conditional division of the markets of countries or regions between transport companies. Today, the competition in the transport market has a pronounced macroeconomic, global character.

Russia, taking into account its own geopolitical significance and geographical potential, is currently showing considerable interest in the full-fledged entry into the market of international transit traffic. In the aspect of freight traffic, to a greater extent this trend can be traced in the segments of railway and water transport. Two major projects can be emphasized here: the development of the Trans-Siberian Railway and the development of the infrastructure of the Northern Sea Route.

\section{Results}

The Northern Sea Route (NSR), as defined by the Federal Law "On Inland Sea Waters, the Territorial Sea, and the Contiguous Zone of the Russian Federation" (1998), is the historically established national unified transport communication of the Russian Federation in the Arctic. Interest in the Northern Sea Route to a greater extent due to the fact that it is much shorter compared to alternative options. For example, between the ports of Hamburg and Yokohama via the NSR, there are only 6,600 nautical miles, while along the Southern Sea Route (SSR),

\footnotetext{
*Corresponding author: kuzminmiit@gmail.com
} 
through the Suez Canal, ships need to overcome about 11,400 nautical miles. As a result, less fuel consumption, less time for transport services, lower costs associated with payment for a crew and provisions, etc. However, there are significant disadvantages caused by the aggressive environment of the northern seas lying in the path of the NSR. First of all, the commercial attractiveness of this transportation option remains low because of the temporary restriction of navigation due to the freezing of water. The climate of the Arctic seas is characterized by short summers and harsh long winters. Therefore, some regions of the sea route pass under heavy ice conditions and require icebreaking support. The navigation period during the year is 5-6 months. The aggressive ice cover of the Arctic seas does not allow many large modern vessels ( $>4.5$ thousand TEU) to sail in their waters. The vast majority of the world's cargo fleet does not have any ice class. Some especially ice-infested sections of the route are not completely thawed even in summer, but it is worth noting that recently, the climate situation in the aspect of development of the transit through the NSR has a rather positive outlook.

Numerous climatic studies of the Arctic regions of the NSR confirm the fact of gradual thawing of glaciers and an increase in the duration of navigation. In 1979, in the summer, the area of glaciers in the Arctic was 7.5 million km2. In 2016 - 4.14 million km2. Since 2002, Greenland has lost 3.6 trillion tons of ice $(<0.15 \%$ of the total weight of the Greenland ice sheet). Expert opinions on the nature of this phenomenon differ. In one case, experts explain warming by a temporary cyclical climate process, in another case - by the greenhouse effect due to the active use of hydrocarbons. One way or another, even with the most negative forecasts, the trend of thawing, taking into account the inertia of natural processes, will continue for several decades [3].

The second barrier hindering the intensive development of commercial shipping along the Northern Sea Route is the poorly developed transport infrastructure of some northern regions of Russia. For example, most of the ports to the east of Dikson (Tiksi, Pevek, etc.) outlived their usefulness and unable to maintain a service of the prospective dimensions of cargo traffic. In particular, for reasons of infrastructural character, large-tonnage vessels cannot enter these ports (modern oil tankers, container trucks over 4.5 thousand TEU, etc.).

This has a negative effect on the safety of navigation, since there is virtually no possibility of operational assistance (using aviation) to ships in distress to the east of the Kara Sea. Nowadays, maritime rescue coordination centers and maritime rescue sub-centers are located in the ports of Murmansk, Arkhangelsk, Dikson, Tiksi, Pevek, Petropavlovsk-Kamchatsky. However, it should be noted that active work is being done in this direction today.

It is also worth noting the weak economic attractiveness of some regions: low density of population and enterprises and, as a result, the lack of an economically viable number of transport services consumers. The exception is the segment of extraction and transportation of hydrocarbon resources. For example, the "Prirazlomnaya" drilling platform is supplied through the port of Murmansk.

The third obstacle to the development of commercial shipping in the Russian Arctic is the imperfection of the legal regulation of the use of transport infrastructure of ports of the special customs control zone. For example, the entry of foreign ships into the port of Tiksi is complicated by the need to collect a large number of permits, which may take months to complete. Norway can be an example of foreign practice on this issue. Customs regulation there is much more liberal and, as a result, shipping is active even in the cruise segment. Changes in the legislation in the field of customs regulation of the northern regions could significantly transform the economic situation of small port settlements located along the route of the NSR. Obviously, the main driver of the development of navigation along the NSR is the cost of oil [4-5]. There are several reasons.

First, the cost of oil directly determines the cost of fuel consumed by ships. In the case of high fuel costs, the economic attractiveness of long routes is lost. Shipping companies are 
actively looking for alternative delivery options. For example, it takes 25 days and 625 tons of fuel oil to go from Europe to China by the Northern Sea Route, while using the Suez Canal - 35 days and 875 tons of fuel oil. Figure 1 shows the dynamics of change in prices for fuel oil according to the New York Commodity Exchange. Over the past 15 years, the cost of fuel oil has increased by more than $250 \%$, and during peak periods, the diference was 6.77 times.

\section{- Price of fuel oil, USD/gallon}

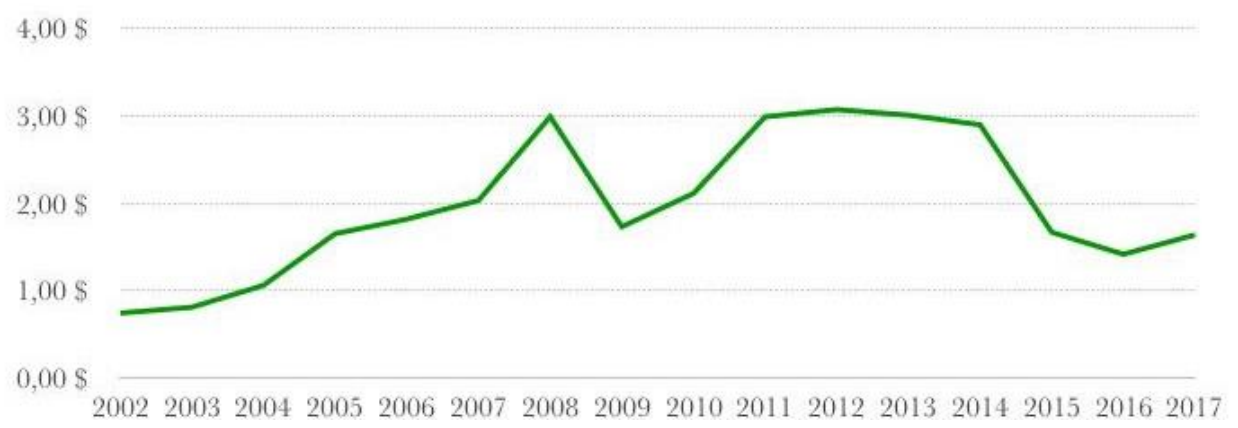

Fig. 1. Dynamics of prices for fuel oil.

If we compare this graph with the statistics of the NSR traffic, then the correlation in terms of the active reorientation of transit cargo flows in different fuel cost periods becomes obvious. Figures 2, 3.

Transit traffic volume, mln tons

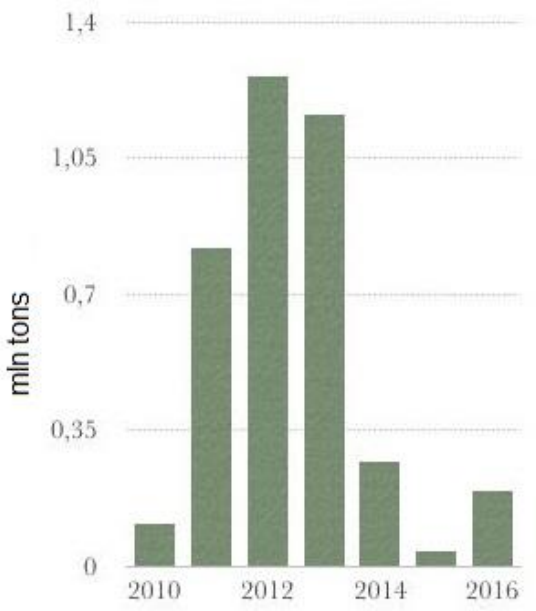

Fig. 2. Transit traffic volume, mln tons.
Number of vessels, pcs

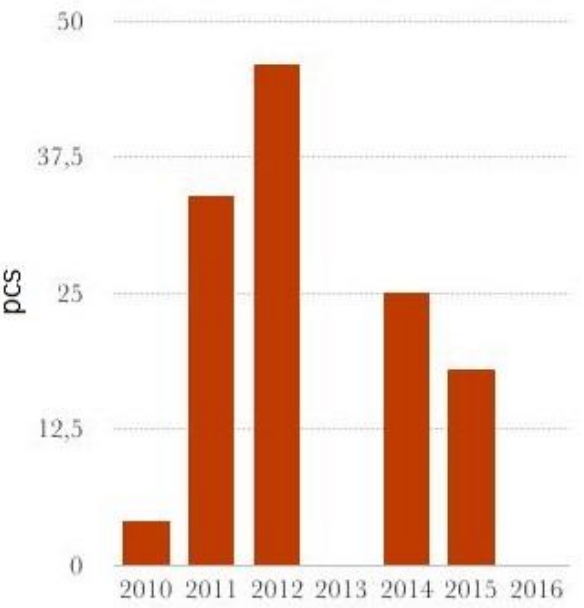

Fig. 3. Number of vessels, pcs.

The greatest demand for commercial freight transit through the NSR was observed in the period of 2011-12, when the peak price of Brent oil on the MOEX exchange was 124.37 USD/barrel. The example of a way around Africa through the Cape of Good Hope can serve as another vivid example of the correlation between the directions of cargo flows and the cost of oil. During the period of low oil prices from October to the end of December 2015, more than 100 commercial vessels passed by Africa and the Suez Canal, despite the significant difference in the length of routes and the length of time the vessels sailed. In December 2015, the price of Brent oil fell to a record 36.2 USD per barrel. In these macroeconomic conditions, 
the share of fuel costs in the cost structure of transportation began to be significantly lower than the costs associated with charges for passing vessels through the Suez Canal, costs associated with cargo insurance and armed escort of vessels due to the fact of piracy in relation to commercial ships passing through the Suez Canal.

Secondly, the high cost of oil and gas makes it profitable to product them in areas of the northern seas, where, due to the specific technology, the production process is more expensive. For example, the cost of oil production at the Prirazlomnoye field in the Pechora Sea is 3-5 times more expensive (about $30 \mathrm{USD} /$ barrel) than to produce oil on land. According to various estimates, the break-even point for oil production in the Arctic is 52-81 $\mathrm{USD} /$ barrel. However, it is worth noting that experts predict that by 2035 , the depletion of reserves of developed Russian fields will be up to $46 \%$, and the development of Russia's Arctic reserves for the future until 2050 can meet up to $30 \%$ of the global oil demand. Most of the Arctic hydrocarbons are concentrated on the territory of the Russian shelf. The cumulative share of Russia's Arctic oil reserves is almost $60 \%$. It is obvious that with the active development of the Arctic fields, the NSR project will be more focused on domestic and export demand. In the cost structure of a barrel of oil, transportation costs associated with the delivery of raw materials from mining sites to consumers depend on many factors, but on average amount to about $10 \%$. Therefore, the relevance of effective transport support to the production regions and the ports serving them will increase.

\section{Conclusions}

Summarizing the above, we can draw the following conclusions:

1. Considering the above, the paramount influence of the economic environment of the global hydrocarbon market on the orientation of marine cargo flows becomes obvious. The cost of oil and, as a result, fuel oil will directly determine the distribution of sea cargo flows in the world.

2. With the most favorable forecasts for rising oil prices ( $>120 \mathrm{USD} / \mathrm{bbl}$ ), modernizing the transport infrastructure of the Northern Sea Route, and changing the customs regulation of the northern regions, the maximum reorientation of cargo traffic from the SSR to the NSR will not exceed $7-10 \%$, which definitely cannot provide this artery with leading transit status in the world.

3. The prospective need for the development of oil and gas fields in the Arctic will require the development of transportation support to these fields and service ports. This circumstance will be the main driver of the development of the Arctic regions of Russia and the NSR in terms of domestic and export consumption of shipping services. The profitability of the development of the NSR in this segment is provided with the cost of oil of $80 \mathrm{USD} /$ barrel and above.

\section{References}

1. The Law of the Russian Federation No. N-155-FZ

2. D.V. Kuzmin, A.V. Baginov, RISC: Resources, Information, Supply, Competition 1, 20-23 (2015)

3. D.V. Kuzmin, V.V. Baginova, Collection of scientific papers 1, 40-44 (2017)

4. A. Flammini, M. Pasetti, S. Rinaldi, P. Bellagente, A. C. Ciribini, et.al. 2018 AEIT International Annual Conference, 3-5 October 2018, Bari, Italy (In Press).

5. S. Rinaldi, M. Pasetti, E. Sisinni, F. Bonafini, P. Ferrari, M. Rizzi, A. Flammini, Energies, 11, 5 (2018), 1220. DOI: 10.3390/en11051220 